\title{
Descautivar o pensamento pedagógico latino-americano: (Des)colonização e (Des)patriarcalização a partir da crítica feminista
}

\author{
Cheron Zanini Moretti ${ }^{1}$, Graziela Rinaldi da Rosa ${ }^{2}$ \\ ${ }^{1}$ Universidade de Santa Cruz do Sul - UNISC. Departamento de Educação/Programa de Pós-Graduação em Educação. \\ Campus Universitário. Santa Cruz do Sul - RS. Brasil. ${ }^{2}$ Universidade Federal de Rio Grande - FURG \\ Autor para correspondência/Author for correspondence: cheron.moretti@gmail.com
}

\begin{abstract}
RESUMO. Nesse artigo, nos propomos a desenvolver as ideias de descautivar, descolonizar e despatriarcalizar a pedagogia a partir de teóricas feministas latino-americanas tomando-as como "fontes", as quais nos ajudam a (re)criar bases epistemológicas de "nosotras", ante as epistemologias dominantes. Trata-se de uma pesquisa qualitativa de cunho bibliográfico que se apoiou em Francesca Gargallo, Luz Maceira Ochoa, Cláudia Korol, Maria Lugones, Marcela Lagarde, entre outras. As suas aproximações e diálogos nos levam à compreensão de "sororidade" e de "ética feminista" como parte imprescindível de um pacto de complexas relações no fortalecimento experiências comuns das mulheres, em especial, quanto ao saber/conhecer, poder e ser. No movimento de transformação da Educação Popular e da Pedagogia, encontramos caminhos para descautivar, descolonizar e despatriarcalizar essas relações, mas também como caminhos para (re)existir e resistir na consubstancialidade entre raça, classe e gênero.
\end{abstract}

Palavras-chave: Descolonização do conhecimento, Despatriarcalização do conhecimento, Epistemologia Feminista, Educação Popular, Pedagogia Latino-americana. 


\title{
Descautivar the Latin American pedagogic thought: (Des)colonization and (Des)patriarchalization from the feminist critique
}

\begin{abstract}
In this paper, we propose to develop the ideas of "descautivar", decolonizing and depatriarchallizing the pedagogy from Latin American theorists feminist, taking them as "sources", which help us (re)create bases epistemological of "us" before the dominant epistemologies. This is a qualitative bibliographic research that was supported by Francesca Gargallo, Luz Maceira Ochoa, Cláudia Korol, Maria Lugones, Marcela Lagarde, among others. Their approximations and dialogues lead us to the understanding of "sorority" and "feminist ethics" as an essential part of a pact of complex relationships in strengthening common experiences of women, especially as to knowing, power and being. In the transformation movement of Popular Education and Pedagogy, we find ways to "descautivar", decolonize and depatriarcalize these relations, but also as ways to (re)exist and resist in the consubstantiality between race, class and gender.
\end{abstract}

Keywords: Knowledge Decolonization, Knowledge Depatrialization, Feminist Epistemology, Popular Education, Latin American Pedagogy. 


\section{Descautivar el pensamiento pedagógico latino americano: (Des)colonización y (Des)patriarcalización a partir de la crítica feminista}

RESUMEN. En este artículo, nos proponemos desarrollar las ideas de descautivar, descolonizar y despatriarcalizar la pedagogía desde teóricas feministas latinoamericanas tomándolas como "fuentes", las cuales nos ayudan a (re)crear bases epistemológicas de "nosotras" ante las epistemologías dominantes. Se trata de una investigación cualitativa de base bibliográfica que se apoyó en Francesca Gargallo, Luz Maceira Ochoa, Cláudia Korol, Maria Lugones, Marcela Lagarde, entre otras. Sus aproximaciones y diálogos, nos llevan a la comprensión de "sororidad" y de "ética feminista" como parte imprescindible de un pacto de complejas relaciones en el fortalecimiento de experiencias comunes de las mujeres, en especial, en cuanto al saber/conocer, poder y ser. En el movimiento de transformación de la Educación Popular y de la Pedagogía, encontramos caminos para descautivar, descolonizar y despatriarcalizar esas relaciones, pero también como caminos para (re)existir y resistir en la consubstancialidad entre raza, clase y género.

Palabras clave: Descolonización del conocimiento, Despatriarcalización del conocimiento, Epistemología Feminista, Educación Popular, Pedagogía Latinoamericana. 


\section{Introdução}

La esperanza de las educadoras populares feministas es que toda la educación popular sea feminista y antiracista, incorporando un análisis de género, usando una metodología integrada y enfocándose en la persona entera. Esta es una metodología que puede usarse con mujeres y hombres en todo tipo de lucha y que representa un paso más en la transformación en marcha de la educación popular (Nadeau, 1996, p. $35)$.

Nas palavras de Denise Nadeau (1996) identificamos a declarada esperança na transformação da Educação Popular através da incorporação, tanto em sua análise quanto em suas metodologias, da perspectiva gênero. Passadas duas décadas desde essa referência à necessidade de enfoque à pessoa em sua integralidade, podemos dizer que as mulheres têm assumido cada vez mais a si próprias como objeto de preocupação na produção acadêmica e científica, além de fortalecer as suas práxis na Educação Popular. Muitos passos foram dados em sua marcha da transformação, como esperava Nadeau, ainda que falte muito para a conquista da igualdade entre gêneros, em especial, na produção e distribuição do conhecimento.

Os lugares e os contextos em que as mulheres se encontram são variados e a consubstancialidade entre classe, raça/etnia e gênero tem ampliado as possibilidades de visibilidades de nosotras ${ }^{\mathrm{i}}$. Assim, as mulheres das florestas e dos povos tradicionais, as indígenas, as quilombolas, as pomeranas, os povos dos mares e as pescadoras, os povos do campo e as agricultoras familiares e as suas práticas sociais têm figurado em estudos mais recentes, contribuindo para romper silenciamentos e invisibilidades. De acordo com Perrot (2017), há discursos e imagens que encobrem as mulheres, assim como também existem muitas "fontes" que falam sobre elas.

Fontes que emanam delas, nas quais se pode ouvir suas vozes diretamente. Podem ser achadas em bibliotecas, local do impresso, dos livros e dos jornais; como nos arquivos público ou privados. Lugares solitários e complementares, que não deveriam ser excludentes, mas que se diferenciam, entretanto, por um grau maior ou menor de espontaneidade discursiva (Perrot, 2017, p. 25-26).

No entanto, para além da identificação desse enclausuramento e discursividade, compreendemos ser relevante ir às próprias mulheres para compreender a produção do "conhecimento situado"ii . De acordo com Lowy "as definições vigentes de neutralidade, objetividade, racionalidade e universalidade da ciência, na verdade, frequentemente incorporam a visão do mundo das pessoas que criaram essa ciência: homens - os machos - ocidentais, 
membros das classes dominantes" (2009, p.40).

Assim, optamos por trabalhar com o pensamento de algumas mulheres que compõem, em nosso entendimento, um conjunto de características que nos levam a compreender seu pensamento como "fontes pedagógicas", ou seja, que têm a ver com a "reconstrução de uma teoria pedagógica que, ao olhar para trás e reencontrar-se com a sua memória, possa ao mesmo tempo se abrir para novos horizontes no presente" (Streck, Adams \& Moretti, 2010, p. 9). Trata-se, também, de uma opção ética, crítica e feminista, uma vez que o feminismo tem sido a contribuição mais importante para a reflexão-ação sobre as condições das mulheres (Lagarde, 2005).

Nesse sentido é que:

Tomamos del feminismo varias pistas para pensar nuestras perspectivas políticas; entre ellas: 1) la crítica a la dominación capitalista y patriarcal; 2) el sistemático cuestionamiento a la cultura androcéntrica; 3) la reflexión que apunta a la deconstrucción de las categorías duales, binarias; 4) la búsqueda de horizontalidad y de autonomía; 5) la valoración del diálogo en la práctica política; 6) la radicalidad en la denuncia de los ordenamientos que pretenden disciplinar el campo de quienes resisten la dominación. (Korol, 2007a, p. 17).
Ao olharmos "desde abajo y desde el Sur" (Carrillo, 2014) para as fontes pedagógicas, observamos caminhos metodológicos para a história do pensamento pedagógico latino-americano. Nesse caminho, que é também epistemológico, se reconstrói a partir do que pensam e fazem as mulheres no campo da educação.

As mulheres como "fontes da/na pedagogia latino-americana" demanda um trabalho de revisão bibliográfica. Nesse caso, em particular, demanda por uma busca exploratória numa perspectiva feminista. Trata-se, ainda, de identificar um campo de saberes e práticas vivos, dinâmicos, e em movimento ${ }^{\mathrm{iii}}$ com as mulheres.

Para um mapeamento inicial, identificamos e listamos as mulheres citadas direta e indiretamente na obra de Paulo Freire ${ }^{\text {iv }}$. Em seguida, identificamos as latino-americanas e a sua vinculação com perspectivas emancipatórias. Com isso, buscamos ampliar nossa revisão de literatura, buscando outras mulheres cujas abordagens já partem dos estudos ou da crítica feminista ao sistema-mundo (patriarcal-colonial-imperial-capitalista).

Fomos às "fontes que emanam delas, nas quais se pode ouvir suas vozes" com vistas à descautivar, despatriarcalizar e 
descolonizar/descolonializar ${ }^{\mathrm{V}}$

o

pensamento pedagógico.

Imagem I: Tríade das bases epistemológicas das "fontes pedagógicas” feministas da/na América Latina.

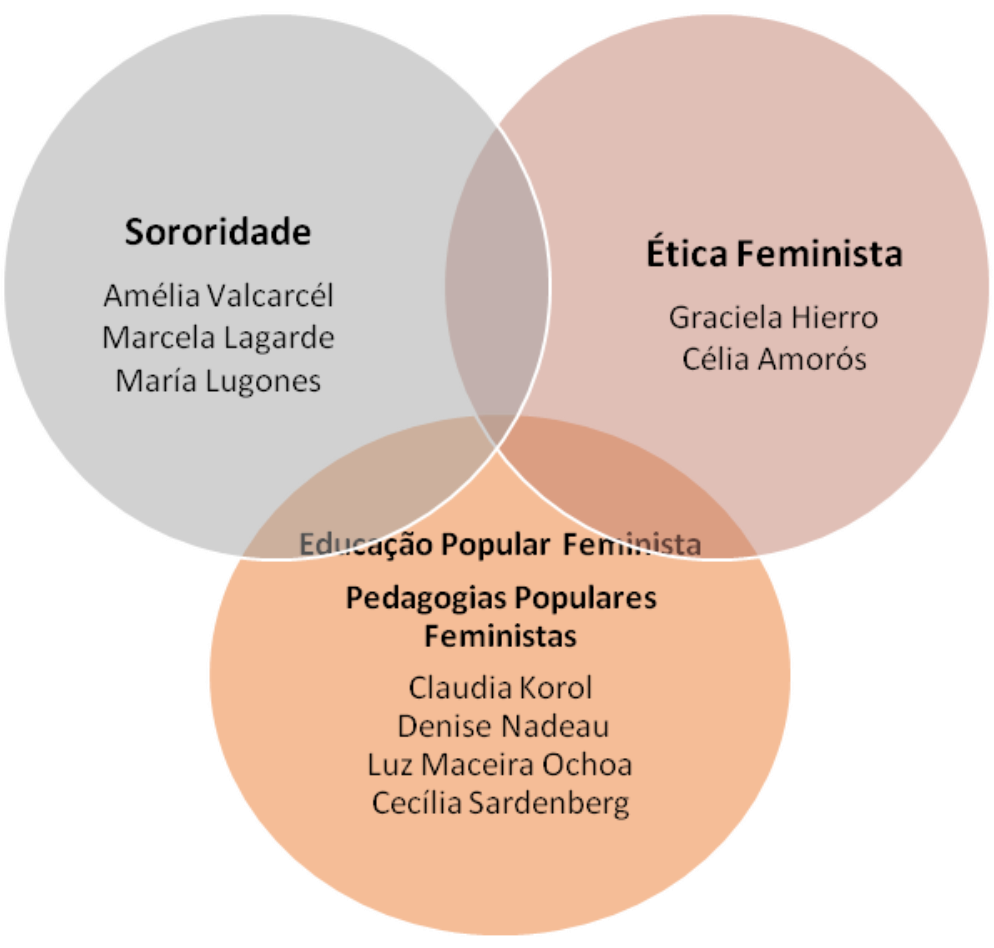

Fonte: Gráfico elaborado pelas autoras (2018).

Para tanto, Hierro (1990) tem nos apoiado para pensar a "ética feminista"; Amorós (1991), Lagarde (1994, 2005, 2006), Saffioti $(2013,2015)$ e Gargallo ${ }^{\mathrm{vi}}$ (2004), nos ajudam quantos às ideias feministas latino-americanas, na perspectiva de despatriarcalizar $\mathrm{o}$ pensamento. Enquanto Ochoa (2008), Korol (2007a, 2007b), Nadeau (1996) e Sardenberg $(2006,2011)$ contribuem para pensar as Pedagogias Feministas, assim como a Educação Popular, Lugones (2008, 2014a, 2014b) nos provoca a refletir numa perspectiva descolonizadora do conhecimento. Já Valcárcel $^{\mathrm{vii}}$ (1997) e, novamente, Lagarde (1994, 2005, 2006) nos inspiram a descautivar as "fontes pedagógicas"viii da/na América Latina e a conhecer mais sobre o "pacto entre as mulheres", chamado "sororidade". Nesse sentido, pudemos compreender que a Educação Popular feminista e as pedagogias populares feministas na América Latina possuem relevantes trabalhos, e potência epistemológica ${ }^{\mathrm{ix}}$. 
Imagem II: Descautivar, Descolonizar e Despatriarcalizar as fontes pedagógicas da América Latina.

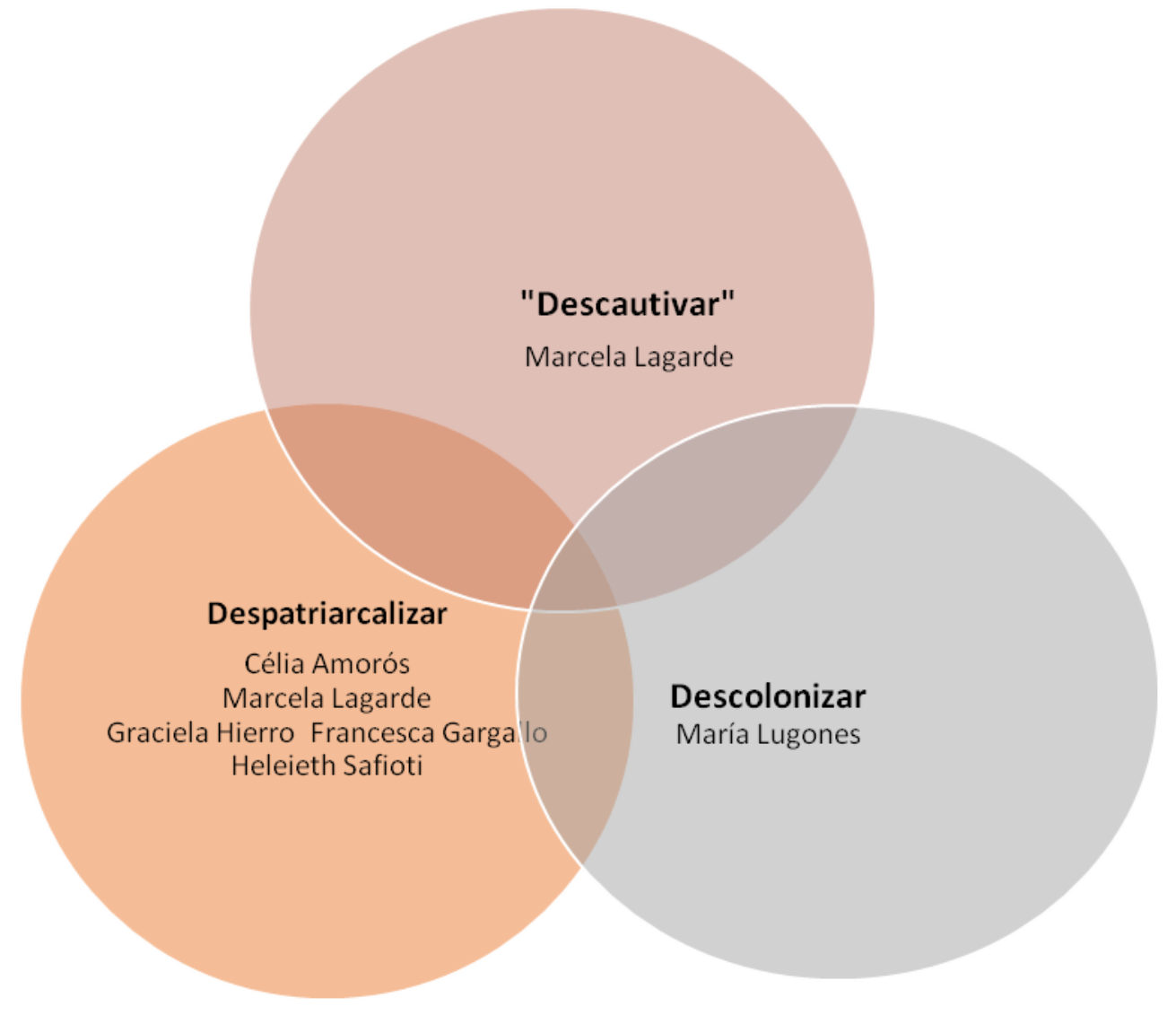

Fonte: Gráfico elaborado pelas autoras (2018).

Nesse artigo, nos propomos a desenvolver a ideia de descautivar, descolonizar e despatriarcalizar a pedagogia a partir de teóricas feministas latino-americanas tomando-as como "fontes", as quais nos ajudam a (re)criar bases epistemológicas de "nosotras". Logo, apresentamos o conceito de descautivar na relação com as ideias de despatriarcalizar e descolonizar a educação e a pedagogia a partir da experiência comum das mulheres. As suas aproximações e diálogos, nos levam à "sororidade" e a "ética feminista" como parte imprescindível de um pacto de complexas relações no fortalecimento experiências descolonizadoras do poder, do saber/conhecer e do ser. A partir da sororidade e da ética feminista apresentamos, também, alguns caminhos epistemológicos para (re)existir e resistir.

\section{Descautivar, Despatriarcalizar e Descolonizar o conhecimento}

Falar de "fontes", nos remete a (re)conhecer mulheres protagonistas da educação na América Latina. Também nos possibilita a aproximação com práticas educativas elaboradas na perspectiva 
feminista, práticas essas que nos possibilitam caminhos para descolonizar, despatriarcalizar e descautivar o pensamento pedagógico latino-americano.

O patriarcado constitui-se a partir da concentração de recursos e propriedade nas mãos dos homens, definindo um sistema de heranças ligados a uma genealogia por via varonil. As mulheres, sendo-lhes atribuído um papel essencialmente circunscrito a casa, foram marginalizadas em relação às instituições de poder político, de transmissão de conhecimento e de formação profissional (Macedo \& Amaral, 2005, p. 145).

A crítica ao patriarcado não é nova. Saffioti (2015, p.111), nos explicou que "há, sem dúvida, uma economia doméstica, ou domesticamente organizada, que sustenta a ordem patriarcal". Nesse sentido, despatriarcalizar significa denunciar também a condição de oprimidas, em que as mulheres vivem, bem como as dominações e opressões que sofrem. "O importante a reter é que a base material do patriarcado não foi destruída, não obstante os avanços femininos, quer na área profissional, quer na representação no parlamento brasileiro e demais postos eletivos políticos" (Saffioti, 2015, p. 112).

Nós mulheres aprendemos as normas patriarcais e as reproduzimos, nos oprimimos entre nós mesmas. Nesse sentido, esse "regime da dominaçãoexploração das mulheres pelos homens"
(Saffioti, 2015, p. 47), também nos ensina a pensar e agir de forma patriarcal, andocêntrica, colonizadora, opressora, contra nós mesmas. E aqui está uma questão central para a educação, a relevância dos estudos feministas nesse campo para ensinarmos e aprendermos com outras gerações a romper com o patriarcado e suas amarras.

Despatriarcalizar significa na problematização aqui apresentada repensar a produção e distribuição do próprio conhecimento, para além das tarefas realizadas (e não realizadas) por gêneros; repensar produções e distribuiç̧ões das noções de identidade de cada um dos sexos, consequentemente das relações de poder, de autoridade e de privilégios; denunciar o favorecimento historicamente tomado pelos homens, em todos os espaços e práticas sociais, bem como nas práticas de ensino; fazer a crítica ao patriarcado no âmbito da educação; estudar outras fontes.

A trama é muito mais complexa do que parece, por isso nos apropriamos do conceito descautivar, de Marcela Lagarde (2005). Ela nos fala dos cativeiros das mulheres e explica que "las mujeres están cautivas porque han sido privadas de autonomía vital, de independencia para vivir, del gobierno sobre sí mismas, de la posibilidad de escoger y de la capacidad de decidir sobre los hechos fundamentales de 
sus vidas y del mundo (Lagarde, 2005, p. 37). Para a feminista mexicana, nesse cativeiro, a autodeterminação e a vida das mulheres é tomada pelas instituições e "pelos outros" através das obrigações com o "ser feminino" materializado nas vidas esterotipadas e sem alternativas. "Todo esto es vivido por las mujeres desde la subalternidad a que las somete el dominio de sus vidas ejercido sobre ellas por la sociedad y la cultura clasista y patriarcales, y por sus sujetos sociales". (Lagarde, 2005, p. 37).

Os cativeiros das mulheres se caracterizam pela falta de liberdade das mulheres. Os cativeiros são lugares que muitas sofrem, vivenciam violências e dores, lugar onde são oprimidas. Por outro lado, explica que nos cativeiros as mulheres também sobrevivem criativamente, e frente às opressões sofridas algumas são felizes. Dessa forma, Lagarde construiu essa categoria "como sínteses del hecho cultural que define el estado de las mujeres en el mundo patriarcal. El cautiverio define politicamente a las mujeres, se concreta en la relación específica de las mujeres con el poder, y se caracteriza por la privación de la liberdad, por la opresión". (Lagarde, 2005, p. 36-37).

Nesse sentido, encontramos nas mulheres como sendo fontes pedagógicas da América Latina, ação-reflexão criadas e realizadas pelas próprias mulheres, muitas dessas feministas, que de maneira criativa, valorizam a subjetividade, e parte dos corpos e vivências de mulheres e meninas para contribuir para uma educação não patriarcal e androcêntrica. São práticas de ensino-aprendizagem, metodologias e leituras que contribuem para que meninas e mulheres compreendam a lógica patriarcal, e reconheçam os cativeiros que as oprimem.

María Lugones $^{\mathrm{x}}$ (2014a) tem nos auxiliado a contextualizar a importância do feminismo numa perspectiva descolonial. Em nossa pesquisa, esse tipo de feminismo nos possibilita conhecer o "sul epistêmico"xi . Enquanto uma teórica da resistência $^{x i i}$, o enfoque de Lugones (2014a) está na crítica à colonialidade do gênero, especialmente, na perspectiva da diferença colonial. De acordo com a sua perspectiva, "descolonizar o gênero é necessariamente uma práxis. É decretar uma crítica da opressão de gênero racializada, colonial e capitalista heterossexualizada visando uma transformação vivida do social" (Lugones, 2014a, p. 940). Assim, falar em descolonialidade não é um tema do passado:

É uma questão da geopolítica do conhecimento. É uma questão de como produzimos um feminismo que 
pegue os desígnios globais para a energia do feminino e masculino racializados e, apagando a diferença colonial, recolha essa energia para usá-la em direção à destruição dos mundos de sentidos de nossas próprias possibilidades (Lugones, 2014a, p. 946, grifos nossos).

Não é novidade que "las necesidades cognitivas del capitalismo y la naturalización de las identidades, y las relaciones de colonialidad, y de la distribución geocultural del poder capitalista mundial han guíado la producción de esta forma de conocer" (Lugones, 2008, p. 80). Podemos dizer que, não é possível pesquisar as mulheres como fontes pedagógicas da América Latina sem romper com a norma hegemônica do sistema-mundo (androcêntrica, machista, misógina e heterossexual).

As primeiras constatações nos conduzem a considerar que a educação e a pedagogia precisam ser analisadas a partir dessa tríade - despatriarcalizar, descolonizar e descautivar. Lagarde (1994), por exemplo, explica que para mudar a ordem patriarcal são necessárias ações de ordem estruturais, no âmbito social, econômico, jurídico e político. As educadoras populares feministas apostam na criatividade. Realizam a crítica, desaprendem e aprendem novos saberes, valores e interpretações para compreender o mundo e a vida, construindo a democracia de gênero, fortalecendo uma sociedade no âmbito de oportunidade de vida e desenvolvimento realmente sustentável para as mulheres.

Korol (2007a; 2007b) nos oferece subsídios para pensarmos uma pedagogia que contribui na construção de espaços reflexivos de práticas contra a cultura patriarcal, enquanto Lagarde (2006) nos ensina a partir da sororidade e Graciela Hierro (1990) a construir uma ética feminista.

Como feministas y educadoras populares, nos proponemos elaborar colectivamente herramientas y aminos que apunten a la construcción de relaciones sociales emancipatorias. Pensamos, imaginamos y proyectamos una emancipación integral, múltiple, compleja, dialéctica, alegre, colorida, diversa, ruidosa, desafiante, libertaria, ética, polifónica, insumisa, rebelde, personal, colectiva, solidaria (Korol, 2007a, p. 3).

Temos na América Latina, pedagogias feministas construídas na esteira da Educação Popular, que encontra na educação não escolarizada um fecundo espaço de atuação. Para a feminista mexicana, Luz M. Ochoa, esse é um espaço adequado para se encontrar elementos ou práticas pedagógicas feministas. Sobretudo, tratando sobre práticas de educação não formal, pode-se identificar características muito 
particulares que surgem das necessidades sociais e de experimentação pedagógica.

Son prácticas educativas alternativas a partir de las cuales se han podido desarrollar cuerpos de conocimiento y métodos de trabajo fundamentales dentro de los movimientos educativos contemporáneos, como la educación popular y la educación para la paz e los derechos humanos. Asimismo son experiencias mucho más abiertas a la incorporación de nuevas inquietudes, a la transformación de los sentidos y métodos pedagógicos, por lo que el feminismo ha podido impactarlas en mayor medida que en el caso de las experiencias escolarizadas. Esto no implica que las reflexiones pedagógicas elaboradas desde este campo no puedam ser extensivas y aplicables a otros ámbitos ... (Ochoa, 2008, p. 29).

Ochoa esclarece em sua obra as razões de buscar na educação não formal ${ }^{\text {xiii }}$ um espaço para as práticas pedagógicas feministas e destaca que, no México, o feminismo tem sido impulsionado pelo diadia do fazer pedagógico e a rotina do âmbito educativo, que a influência do feminismo no sistema escolar mexicano é até hoje, limitada, se comparada com outros países (Ochoa, 2008). As experiências desenvolvidas dentro do sistema escolar são mais conhecidas, mais analisadas e sistematizadas, contando ainda com recursos necessários para seu desenvolvimento e avaliações. Ela nos explica ainda que:
... esto no implica que las reflexiones pedagógicas elaboradas desde este campo no puedan ser extensivas y aplicables a otros ámbitos, la pedagogía freireana, surgida en un contexto muy particular ha podido ser retomada en prácticas educativas de lo más diversas, por lo que reflexionar y teorizar desde este campo, abierto y más flexible, no excluye desde mi punto de vista, que el campo de acción inicial pueda y deba ampliarse a otros. (Ochoa, 2008, p. 29-30, grifos nossos).

Sendo assim, as reflexões que apresentamos a seguir possuem uma intrínseca relação epistemológica, e são necessárias para pensarmos na perspectiva feminista que, por questões éticas e de solidariedade, têm apostado na despatriarcalização e descolonização do poder, do ser e do saber/conhecimento. E, como anunciamos anteriormente, em descautivar o pensamento/ideias pedagógicas na/da América Latina.

\section{A sororidade e a ética feminista: caminhos para a epistemologia de "nosotras"}

As epistemologias feministas têm contribuído para pensar as ciências ${ }^{\mathrm{xiv}}$, assim como para pensar a ciência $\operatorname{popular}^{\mathrm{xv}}$, em especial, para uma educação popular que serve para a libertação/emancipação das mulheres, uma vez que: 
La "práctica de la libertad" no se limitaría así a un discurso contra las formas opresivas y represivas del Estado burguês y patriarcal, de sus instituciones de reproducción de la cultura capitalista, androcéntrica, colonizadora. Es sobre todo la posibilidad de un ejercicio de lucha material y también subjetiva contra la enajenación, contra la mercantilización de nuestras vidas, la privatización de nuestros deseos, la domesticación de nuestros cuerpos, la negación sistemática de nuestros sueños, la mutilación de nuestras rebeldías, la invisibilización de nuestras huellas, el silenciamiento de nuestra palabra, y la desembozada represión de nuestros actos subversivos (Korol, 2007b, p. 17).

A partir da ideia de que as mulheres possuem epistemologia própria (comum), percebeu-se que há uma intrínseca relação entre a ética feminista e a sororidade com a Educação Popular e a pedagogia crítica na América Latina. Elas juntas, impulsionam práticas e teorias que buscam fortalecer as relações democráticas e emancipatórias, colaborando para o fortalecimento de políticas públicas para as mulheres, contribuindo para o acesso e a conquistas de direitos e a participação de nosotras em diferentes espaços e poder público; também, possibilita o fortalecimento de processos educativos e pedagógicos.

Podemos considerar que, esse movimento de (re)conhecimento das produções feministas gestadas a partir da sua crítica ao sistema-mundo, é parte de uma "ética feminista"xvi, conhecida e vivenciada por algumas mulheres. De acordo com Graciela Hierro (1990), quando as educadoras populares feministas assumem seus trabalhos como uma "Pedagogia Feminista", fortalecem uma ética própria. Assim, entende-se por "ética feminista" o comportamento e as ações que se posicionam contra os mecanismos de exploração e de opressões de um sexo sobre outro. Para Amorós, "una ética feminista es una ética del reino de la necesidad por partida doble: es la lucha por un tipo de sociedade en la que todos los indivíduos puedan plantearse sus problemas en términos éticos" (1991, p. 111).

Assim como Rosa Maria Rodríguez Magda (1997), problematizou algumas estratégias para uma crítica filosófica feminista, é emergente que no campo da educação e da pedagogia, possamos criar estratégias a partir do pensamento-ação das mulheres, pois as mulheres não apenas são a maioria atuando nos espaços de educação, mas também porque têm pensado e teorizado sobre as suas experiências.

Buscamos aqui estabelecer relações com o que Marcela Lagarde denominou de "sororidade"- um pacto entre nosotras. De acordo com a feminista mexicana,

... para pactar, es preciso reconocer que la cultura femenina tradicional vigente entre nosotras, no incluye 
conocimientos, habilidades $\mathrm{y}$ destrezas para agendar ni pactar. Que muchas aprendemos en el estilo masculino y patriarcal para luego desaprenderlo al sentir cuán contradictorio es conducirnos así entre nosotras, lo estéril de esse proceder y la necesidad de construir la alianza entre las mujeres desde una posición política de género. (Lagarde, 2006, p. 124).

Busca-se reconhecer e denunciar que a educação ainda sofre influência do patriarcado. Por exemplo: quando citamos poucas mulheres e citamos pouco as mulheres que elaboraram teorias educacionais, metodologias de ensino e de pesquisa, suas propostas epistemológicas, nossos referentes podem ser muitos outros que não aqueles produzidos por/com as mulheres. ${ }^{\text {xvii }}$ Assim, "para descautivar es preciso dar pasos hacia un horizonte histórico en el cual sean posibles los fundamentos mínimos de la liberdad genérica (Lagarde, 2005, p. 21).

Outra vez, tomando Marcela Lagarde (2006) como nossa dialogante, temos que considerar o "alerta" para o fato de necessitarmos do apoio uma das outras ante a essa trama patriarcal. Esse apoio é denominado por ela de "apoyo cómplice", que muitas vezes recebemos de uma tia, de uma irmã, da sogra, de uma cunhada, das avós, das amigas e de muitas outras mulheres, próximas ou distantes. Nesse sentido, a sororidade nada mais é do que uma aliança feminista entre as mulheres, estabelecida para continuar existindo e, por fim, mudar nossas precárias condições de vida, as violências que sofremos, exclusões e silenciamentos. Etimologicamente “enuncia los principios ético-políticos de equivalencia y relación paritária entre mujeres" (Lagarde, 2006, p. 126).

Assim, ao tratar desse conceito, Lagarde (2006) desenvolve o que consideramos uma reivindicação ética e política. Pois, na medida em que denuncia o patriarcado e sugere que as mulheres pactuem para romper com todas as formas de opressões, ela reivindica um apoio cúmplice entre as mulheres que "cura e cuida". Dessa forma, essa feminista nos provoca a pensar:

Qué habría sido de las mujeres en el patriarcado sin el entramado de mujeres alrededor, a un lado, atrás de una, adelante, guiando el camino, aguantando juntas? Qué seria de nosotras sin nuestras amigas? Qué seria de las mujeres sin el amor de las mujeres? (Lagarde, 2006, p. 124).

De nossa parte: $O$ que seria da educação (das próprias mulheres) sem conhecer o que fazem e o que teorizam as próprias mulheres sobre a educação e pedagogia? Como poderíamos problematizar a origem do conhecimento se os saberes das mulheres não são valorizados, se nos é negado o direito de pensar epistemologicamente ${ }^{\text {xviii }}$ 
Nesse sentido, entendemos que ao tomarmos as mulheres como fontes pedagógicas, seus saberes e fazeres, estamos tecendo alianças, estabelecendo pactos que não implica subsumir conflitos, mas colocar em relevo uma posição política de gênero (Lagarde, 2006). Ao questionar e ao procurar estabelecer relação entre a sororidade e as epistemologias feministas, percebe-se que na medida em que somos solidárias com nosotras, e buscamos desmontar a cultura patriarcal, colonial e misógina, que ainda se faz presente em nosso cotidiano, e que estamos olhando para nossos trabalhos, demandas e histórias de vidas, estabelecemos uma aliança e pactos, mesmo que esses não sejam ditos. De um modo geral, o "não dito" permanece entre as mulheres, mas são resignificados. Uma suspeita é que possam ser compreendidos como resistências.

A sororidade possui, portanto, dimensões ética e política. Lagarde (2006) explica que, além disso, a sororidade é também a

... práctica del feminismo contemporáneo. Es una experiencia de las mujeres que conduce a la búsqueda de relaciones positivas y a la alianza existencial y política, cuerpo a cuerpo, subjetividad a subjetividad con otras mujeres, para contribuir con acciones específicas a la eliminación social de todas las formas de opresión y al apoyo mutuo para lograr el poderío genérico de todas y al empoderamiento vital de cada mujer (Lagarde, 2006, p. 126).

Podemos dizer que a relação entre a ética feminista e a sororidade é complexa. Não somos "naturalmente" solidárias, e somos educadas através de relações de poder patriarcal. Dessa forma, fomos/somos educadas a pensar de forma androcêntrica. Essa educação produz a ausência da ética feminista em nossas relações cotidianas, desencadeia uma equivocada compreensão de sororidade, já apontada por Amelia Valcárcel $^{\mathrm{xix}}$. No entanto, essa mudança paradigmática não é impossível, e a educação despatriarcal pode contribuir muito para superarmos os abismos que existem entre a ética feminista e a sororidade.

Tanto Valcárcel (1994) quanto Lagarde (2006) fazem a crítica ao "individualismo" das mulheres, e contribuem para pensarmos que os homens se apropriaram historicamente dos espaços públicos. E, portanto, a linguagem e os pactos que estabeleceram, os fortaleceram, e os fortalecem até nossos dias. Os homens não pactuam com nosotras, monopolizam a fala, e sua linguagem é espontânea e "abusiva". Nesse sentido, como nos aponta Valcárcel (1994, p. 135):

... con idéntica espontaneidad los varones dejan a las mujeres fuera de cualquier tipo de pacto en el que se 
estabelece el rango o el domínio", e "por lo común los varones no pactan con las mujeres sino la relación doméstica, a menudo incardinada en la sexual, cualquier otro pacto no suele entrar en su sistema selectivo de percepciones.

O fato dos homens não pactuarem com nosotras, demonstra que a sororidade é "un pacto político entre pares" (Lagarde, 2006, p. 126). Nesse sentido, as mulheres que atuam na Educação Popular, numa perspectiva feminista, contribuem no processo de descautivar, descolonizar e despatriarcalizar através do pacto entre nosotras. Necessitamos estabelecer conjuntamente os prazos, os objetivos e os métodos para, então, anunciar nossos sonhos, nossos temas, nossas pesquisas, nossas vozes em comunhão. Trata-se de uma questão de existência, ou seja, se não pactuarmos, não existiremos como produtoras de conhecimentos, não compartilharemos do poder e seguiremos alienadas de nosso ser; nossos temas continuarão sendo pouco estudados e pouco conhecidos, e nossas teorias no campo educacional não repercutirão em transformações no campo epistemológico, e no cotidiano das práticas educativas e pedagógicas.

Porém, é necessário também colocar atenção nas relações sociais existentes nas opressões específicas. Ao apresentar o sistema de gênero moderno/colonial e fazer uma crítica ao feminismo do século $\mathrm{XX}$,
María Lugones explica que as feministas brancas assumiram uma irmandade, uma sororidade, mas não perceberam as profundas diferenças entre si, e ela diz:

Concibieron a 'la mujer' como un ser corpóreo y evidentemente blanco pero sin conciencia explícita de la modificación racial. Es decir, no se entendieron a sí mismas en términos interseccionales, en la intersección de raza, género, y otras potentes marcas de sujeción o dominación. Como no piercibieron estas profundas diferencias... [a]sumieron que había una hermandad, una sororidad, un vínculo ya existente debido a la sujeción de género. (Lugones, 2014b, p. 70).

A crítica quanto à ausência das conexões entre raça/etnia, classe, gênero e sexualidade, indica também que as produções teóricas realizadas ao longo do século XX, no próprio desenvolvimento do feminismo, estabeleceu uma caracterização racializada e classista sobre a emancipação feminina, tanto quanto ao que se refere na experiência do "ser mulher" e de seu conhecimento. De acordo com a crítica descolonial de Lugones, houve um feminismo que enfocou sua luta, suas formas de conhecer e de teorizar, em desconstruir a "fragilidade do sexo";

Pero no explicitó la relación entre estas características y la raza, ya que solamente construyen a la mujer blanca y burguesa. Dado el caráter hegemónico que alcanzó el análisis, no solamente no explicitó sino que 
oculto la relación. Empezando el movimiento de 'liberación de la mujer' con esa caracterización de la mujer como el blanco de la lucha, las feministas blancas se ocuparon de teorizar el sentido blanco de ser mujer como si todas las mujeres fueran blancas (Lugones, 2014b, p. 68.).

María Lugones nos desafia ir além, a pensar que uma epistemologia feminista pactos por questões de gênero e classe, assim como também a tomar em consideração a dimensão racializada da opressão. Assim, a compreensão de "sororidade", um pacto entre mulheres, diz respeito às mulheres que experienciam uma opressão em comum, mas são diversas ao mesmo tempo. Construir esse pacto de complexas relações poderá fortalecer experiências descolonizadoras do poder, do saber/conhecer e do ser.

A partir da sororidade e da ética feminista podemos considerar alguns caminhos epistemológicos para (re)existir e resistir.

\section{Caminhos para (re)existir e resistir}

As perspectivas das epistemologias descoloniais conduzem para os feminismos descoloniais, assim como para a educação e a pedagogia descolonial. Se por um lado, encontramos um feminismo marcado pela resistência, que olha para mulheres de muitas cores, de muitas culturas e de muitos lugares e de espaços, ou seja, naquelas que resistem à colonialidade do gênero a partir da "diferença colonial”, por outro lado, a sua experiência nos remete a outra educação popular e a outra pedagogia. A sororidade e a ética feminista abrem brechas ante o paradigma dominante na epistemologia para epistemologias produzidas desde a experiência comum de ser mulher em sua integralidade, na rede complexa de suas múltiplas determinações.

Lugones (2014a, p. 946), afirma que:

Ver a colonialidade é ver a poderosa redução de seres humanos a animais, a inferiores por natureza, em uma compreensão esquizoide de realidade que dicotomiza humano de natureza, humano de não-humano, impondo assim uma ontologia e uma cosmologia que, em seu poder e constituição, indeferem a seres desumanizados toda humanidade, toda possibilidade de compreensão, toda possibilidade de comunicação humana ... Assim, ver a colonialidade é revelar a degradação mesma que nos dá duas interpretações da vida e um ser interpretado por elas. A única possibilidade de tal ser jaz em seu habitar plenamente esta fratura, esta ferida, onde o sentido é contraditório e, a partir desta contradição, um novo sentido se renova.

O feminismo descolonial, problematizado por María Lugones, a partir da crítica ao próprio feminismo, toca temas que tem muito a contribuir com nosso trabalho de identificação e problematização da pedagogia latinoamericana, tomando as mulheres como 
fontes de uma relação teórico-prática própria, autêntica.

No feminismo descolonial, em especial, na perspectiva de Lugones (2014b, p. 61):

\begin{abstract}
Solo al percibir género y raza como entretramados ofusionados indisolublemente, podemos realmente ver a las mujeres de color. Esto implica que el término 'mujer' en sí, sin especificación de la fusión no tiene sentido o tiene un sentido racista, ya que la lógica categorial históricamente ha solamente el grupo dominante, las mujeres burguesas blancas hererosexuales y por lo tanto ha escondido la brutalización, el abuso, la deshumanización que la colonialidad del género implica.
\end{abstract}

Suas problematizações propõem um "giro paradigmático" que analisam as mudanças nas estruturas sociais, construídas a partir do capitalismo eurocêntrico colonial/moderno que, apesar de heterogêneo, gradual e descontínuo significou na inferiorização das mulheres colonizadas. Assim, a "metodologia da descolonialidade" se dá partir das cosmologias que informam o ser social, "em vez de começar com uma leitura gendrada das cosmologias que subjazem e constituem a percepção, a motilidade, a incorporação e a relação" (Lugones, 2014a, p. 944). Logo, o giro a que se refere e a que se propõe é muito diferente de um que "lê o gênero no social". Lugones deixa claro que se propõe "a entender a resistência à colonialidade do gênero a partir da perspectiva da diferença colonial" (2014a, p. 940), que implica compreender que "descolonizar" é necessariamente uma práxis. "É decretar uma crítica da opressão de gênero racializada, colonial e capitalista heterossexualizada visando uma transformação vivida do social (Lugones, 2014a, p. 940).

O conceito de resistência está presente na proposta do feminismo descolonial de Lugones. Na medida em que ela teoriza a resistência, descoloniza o gênero. A teoria é necessariamente prática e com ela se relaciona. Aqui encontramos a relação entre (re) existir e descolonizar no seu pensamento feminista descolonial. Sendo um feminismo descolonial, a resistência é vista como um começo. A resistência é a tensão entre a sujeitificação e a subjetividade ativa (Lugones, 2014a, p. 940). Trata de um feminismo que tem uma forte ênfase na intersubjetividade historicizada.

Para Gargallo (2004), reivindicar um campo específico na história das ideias filosóficas latino-americana requer um duplo desafio:

Implica el reconocimiento de la historicidad de las ideas feministas en un ámbito cultural mayoritariamente occidentalizado, pero no central ni monolítico y, a la vez, la idea de que el feminismo debe situarse como una teoria política de la alteridad, tanto en su etapa emancipadora, cuando las 
mujeres piden ingresar en condiciones igualitarias en la historia del hombre, como en su etapa de liberación y reivindicación de la diferencia, cuando las mujeres cuestionan y se separan del modelo masculino planteado como universalmente válido (Gargallo, 2004, p. 25).

Cabe ressaltar a importante contribuição de Francesca Gargallo (2004), que problematiza as ideias feministas latino-americanas, ensinando que citar a outras mulheres é um ato político. Na sua obra "Las ideas feministas latinoamericanas", Gargallo apresenta diferentes momentos do feminismo latino-americano, faz a crítica ao patriarcado e pela forma que nós mulheres somos educadas a pensar, apontando a necessidade de reconstruirmos a história das ideias na América Latina, na perspectiva feminista. Com isso, denuncia as interpretações hegemônicas da filosofia latino-americana, o desconhecimento do pensamento que teoriza a partir do escravismo, da colonização, dos povos originários, da subjetividade, dentre outros.

Despatriarcalizar e descolonizar as fontes do pensamento pedagógico latinoamericano implica estabelecermos pactos entre iguais (na sua diversidade) e ética comprometida com a emancipação das mulheres. Esse conjunto de problematizações e reflexões levam a que consideremos a exigência de uma dupla tarefa, a do reconhecimento da historicidade do pensamento pedagógico próprio das mulheres, bem como a busca da emancipação no reconhecimento de sua diversidade. É nesse sentido que a Educação Popular e a pedagogia popular se ressignificam com a epistemologia feminista, na resistência e na (re)existência em comunhão com experiências de sororidade e de ética.

\section{Algumas considerações para continuar "pelos caminhos" do giro epistêmico}

Cabe destacar que há poucos artigos e poucas obras dedicadas ao pensamento pedagógico de mulheres latino-americanas. Mesmo em obras específicas sobre o tema, as mulheres são a minoria. Esse fato é reflexo da influência do patriarcado, e suas relações de poder, de ser e de saber/conhecer no campo da educação. Reafirmando assim, que o patriarcado nega às mulheres não apenas o acesso à educação, ao trabalho, à igualdade social e às melhores condições de vida, mas as silenciam ao negar voz às suas ideias e às suas concepções pedagógicas.

Quando falamos de descolonizar, despatriarcalizar e descautivar o pensamento pedagógico, buscamos denunciar as lógicas internas de dominação e inferiorização da mulher, e contribuir para um pensamento descolonial crítico, 
olhando para a experiência comum de nosotras no campo da educação popular e da pedagogia latino-americana. Nesse sentido, buscamos a que as palavras, as concepções epistemológicas de mulheres acompanhem o movimento de libertação compartilhada entre mulheres. Queremos (re)conhecer que há uma pedagogia latinoamericana com uma perspectiva feminista em construção e que nela encontramos novos temas, novos sujeitos e outras pedagogias, concebidas a partir das epistemologias feministas. Trata-se de uma ousada tarefa, que necessita se distanciar do tradicional esquema de pensamento pedagógico, e estabelecer diálogos entre os referenciais latino-americanos e os estudos feministas.

Novas inquietações a partir das (re)leituras das epistemologias feministas latino-americanas podem ser abertas a partir dessas provocações, aqui apresentadas. Desse modo, procuramos destacar a seguinte questão: Por que descautivar, descolonizar e despatriarcalizar as "fontes" pedagógicas latino-americanas? Por que fazê-lo à luz de uma epistemologia feminista?

Após a fundamentação teórica e pesquisa bibliográfica acerca das mulheres das/nas fontes pedagógicas, e dos conceitos-chave, ampliamos nossa concepção de educação e de pedagogia, a partir das perspectivas feministas sobre ética e sororidade. Também, aproximamos a ideia de descautivar às de despatriarcalizar e de descolonizar como forma de apresentar as nossas próprias amarras, mas também as resistências e (re)existência. Assim mesmo, "la superación de los cautiverios de las mujeres es una de las vías del feminismo (Lagarde, 2005, p. 780), ou seja, das diferentes formas de aceitação da condição de gênero e da situação ante a vida.

Mesmo que não tenha sido nosso objetivo desenvolver marcos referentes com relação ao uso de conceitos de "Educação Popular Feminista", "Pedagogias Feministas" e/ou "Pedagogias Populares Feministas", a nossa pesquisa tem problematizado o lugar da epistemologia feminista em cada um desses outros lugares da ação-reflexão crítica, e promover uma inquietação quanto ao lugar das mulheres nas ideias da Pedagogia Latino-americana.

Além disso, percebe-se que não temos como despatriarcalizar sem descolonizar, ou ainda descautivar. Tratase de uma trama que as feministas vêm construindo. A partir da perspectiva descolonizadora de María Lugones pensamos as epistemologias feministas desde o feminismo descolonial, um feminismo que trabalha com os conceitos 
de "(de)colonialidad y género", e que investiga a consubstancialidade entre raça, classe e gênero.

Com esse artigo, reafirmamos que o feminismo é subversivo, caso contrário não seria transformador. A subversão não é doutrinável e não se sujeita frente às hierarquias, e por isso, não deve reproduzir a colonialidade, o patriarcado e os cativeiros às mulheres. A relação entre a ética feminista e a sororidade contribui para pensarmos as experiências em Educação Popular e as pedagogias populares na América Latina, suas respectivas e múltiplas metodologias, sem medo de usar o qualificativo de feminista junto ao de popular, assumindo-as como parte de uma educação e de uma pedagogia carrega em $s i$ as histórias de vidas e práxis educativas que potencializam os saberes e os fazeres de mulheres que vivenciam, trabalham e sofrem na pele a realidade de serem mulheres latino-americanas. Dessa forma, o "em si" subversivamente vai transformando-se em "para si": uma epistemologia de nosotras. Essa tríade nos fortalece enquanto pensadoras e militantes no campo da Educação Popular, e nos ajuda a (re)pensar a resistência e a (re)existência feminista na história das ideias pedagógicas, assim como na legítima reivindicação da diversidade no processo emancipador humano.
Não se tem a pretensão de esgotar o tema, mas reconhecer que as feministas ampliaram e ampliam no seu cotidiano possibilidades de recriar epistemologias, na medida em que fazem a crítica feminista e (re)pensam suas obras, seus conceitos, a linguagem, seus temas, seus problemas e sujeitos/as.

\section{Referências}

Amorós, C. (1991). Hacia una Crítica de La Razón Patriarcal. Barcelona: Anthropos.

Carrillo, A. T. (2014). Hacer historia desde Abajo y desde el Sur. Colômbia: Ediciones desde Abajo.

Gargallo, F. (2004, 20 de março de 2018). Las ideas feministas Latinoamericanas. Ediciones: fem-e-libros creatividad feminista. México. Recuperado de: $<$ http://herbogeminis.com/IMG/pdf/ideas_f eministas_latinoamericanas.pdf $>$.

Harding, S. (1996). Ciencia y Feminismo. Madrid: Morata.

Hierro, G. (1990). Ética e Feminismo. México: Textos universitários. Universidad Autónoma de México.

Hirata, H. (2014). Gênero, classe e raça. Interseccionalidade e consubstancialidade das relações sociais. Tempo Social, 26(1) 61-73.

Lowy, I. (2009), "Ciências e gênero". In Hirata, H. et al. (Orgs.). Dicionário crítico do feminism (pp. 40-44). São Paulo, SP: Editora da Unesp.

Korol, C. (Org.). (2007a). Hacia una pedagogia feminista. Géneros y educación 
popular. Colección cuadernos de Educación Popular. Buenos Aires: Editorial El Colectivo/América Libre.

Korol, C. (2007b). "La Educación como práctica de la liberdad". Nuevas lecturas posibles. In Korol, C. (Org.). Hacia una pedagogia feminista. Géneros y educación popular (pp. 9-22). Buenos Aires: Colección cuadernos de Educación Popular. Editorial El Colectivo/América Libre.

Lagarde, M. (2006). Pacto entre mujeres sororidad. p. 123-135. Recuperado de https://www.asociacionag.org.ar/pdfaporte s/25/09.pdf.

Lagarde, M. (2005). Los cautiverios de las mujeres: De madreesposas, monjas, presas, putas y locas. México: UNAM.

Lagarde, M. (1994). Democracia genérica. Red Latinoamericana de Educación Popular entre Mujeres. REPEM. México.

Lugones, M. (2014a). Rumo a um feminismo descolonial. Revista Estudos Feministas, 22(3), 935-952.

Lugones, M. (2014b). Colonialidad y Género. In: Miñoso, Y. E.; Correal, D. G.; Muñoz, K. O. (Editoras). Tejiendo de otro modo: Feminismo, epistemologia y apuestas descoloniales en Abya Yala. (pp. 57-90). Popayán: Editorial Universidad del Cauca.

Lugones, M. (2008). Colonialidad y Género. Revista de Humanidades Tabula Rasa, 9, 73-101.

Macedo, A. G., \& Amaral, A. L. (Orgs.). (2005). Dicionário da Crítica Feminista. Porto: Edições Afrontamentos.

Magda, R. M. R. (Ed.). (1997). Mujeres en la historia del pensamiento. Barcelona: Editorial Anthropos.
Nadeau, D. (1996). Educación Popular Feminista: Creando una nueva teoría y práctica. Palabra de mujer, 33-35. Aquelarre. Summer/Fall.

Ochoa, L. M. (2008). El sueño y la práctica de sí. Pedagogía Feminista: una propuesta. México: El Colégio de México, Centro de Estudios Sociológicos, Programa Interdisciplinario de Estudios de la Mujer.

Perrot, M. (2017). Minha história das mulheres. São Paulo, SP: Contexto.

Rago, M. (2012). Epistemologia Feminista, Gênero e História. Descobrindo historicamente o gênero. Compostela: CNT.

Rosa, G., \& Silva, M. A. (2017). Práticas educativas feministas no Brasil: perspectivas epistemológicas antipatriarcais e a pedagogia feminista. In Amaro, S., \& Durand V. (Orgs.). Veias feministas: memória, desafios $e$ perspectivas para a mulher no século 21. (pp. 97-119). Porto Alegre, RS: Bonecker.

Saffioti, H. (2015). Gênero, patriarcado e violência. São Paulo, SP: Editora Fundação Perseu Abramo.

Saffioti, H. (2013). A mulher na sociedade de classes. Mito e Realidade. São Paulo, SP: Expressão Popular.

Sardenberg, C. (2006). Pedagogias feministas: uma introdução. In Vanin, I., \& Gonçalves, T. (Orgs.). Caderno Gênero e Trabalho, 44-57.

Sardenberg, C. (2011). Considerações Introdutórias às Pedagogias Feministas. In Costa, A. A. A., Rodrigues, A. T., \& Vanin, I. M. (Orgs.). Ensino e Gênero: perspectivas transversais (pp. 17-32). Salvador, BA: Núcleo de Estudos Interdisciplinares sobre a Mulher (NEIM). 
Streck, D. R., Adams, T., \& Moretti, C. Z. (2010). Pensamento pedagógico em nossa América: uma introdução. In STRECK, Danilo R. (Org.). Fontes da pedagogía latinoamericana. Uma antología (pp. 1936). Belo Horizonte, MG: Autêntica Editora.

\section{Valcárcel, A. (1997). La política de las mujeres. Madrid: Cátedra.}

Valcárcel, A. (1994). Sexo y filosofia. Sobre "mujer y "poder". Barcelona: Anthropos; Santafé de Bogotá: Siglo del Hombre.

\footnotetext{
${ }^{\mathrm{i}}$ Usamos esse termo em espanhol para indicar um sentido de experiência comum à vida das mulheres latino-americanas, não apenas de lugar que ocupam e/ou papel que desempenham na sociedade, mas quanto à dimensão histórica das relações sociais de classe, raça e gênero. Quanto ao conceito de consubstancialidade, sobretudo agregado à ideia de nosotras, expressa a complexidade de ser mulher. Para a compreensão do termo "consubstancialidade", indicamos a leitura de Hirata (2014).
}

ii Não temos a intenção de desenvolver uma discussão específica sobre o "conhecimento situado" das mulheres do campo. No entanto, entendemos que a discussão apresentada a partir da epistemologia feminista diz respeito ao sujeito coletivo "mulher". Da mesma maneira, não é nossa intenção problematizar a trajetória histórica da Educação do Campo, tampouco trata-lo como sinônimo de Educação Popular. Mas, sim, compreendemos que se encontram na crítica à educação tradicional e/ou excludente.

iii Essa busca permitiu-nos um "encontro" com as ideias de "Educação Popular Feminista", "Pedagogias Feministas" e "Pedagogias Descoloniais" que, em alguma medida, encontramse na denúncia sobre a ausência das mulheres na produção do conhecimento e no anúncio de epistemologias próprias.

iv A Leitura e fichamento da obra de Paulo Freire foi parte da pesquisa de pós-doutoramento de Sandro de Castro Pitano, na UNISINOS, "Articulações teóricas e metodológicas do pensamento de Paulo Freire: diálogos explícitos, implícitos e possíveis". A partir desse projeto foi reunido um conjunto de informações sobre a presença de mulheres como parte importante do pensamento pedagógico desse educador em 32 livros publicados em língua portuguesa, no Brasil. Participamos dessa pesquisa através da vinculação de dois Grupos de Pesquisa, a saber: "Mediações Pedagógicas e Cidadania" (UNISINOS) e "Educação Popular, Metodologias Participativas e Estudos Decoloniais" (UNISC).

v Ao longo de todo artigo utilizamos o termo "descolonizar", em sua particularidade, mas também como sinônimo de "descolonializar".

vi Francesca Gargallo é uma pesquisadora e feminista italiana que tem atuado no ensino superior e realizado estudos no México e na América Latina sobre feminismo autônomo, mulheres indígenas e populares, além de dissidências sexuais e Direitos Humanos.

vii Amelia Valcárcel é uma filósofa feminista espanhola cujos estudos dialogam com as feministas latino-americanas. Por essa razão, a incluímos em nossos diálogos e reflexões.

viii É importante destacar que não estamos utilizando o termo "fontes" como usualmente encontramos na historiografia, uma vez que não temos a intenção de realizar uma reconstrução de um fenômeno histórico, em específico, para a sua compreensão. Muito embora, com isso, desejamos valorizar o que é imanente das práxis das mulheres, colocando em relevo o trabalho de estudiosas feministas em diálogo com a educação e a pedagogia latino-americana.

${ }^{\text {ix }}$ Como Grupo de Pesquisa, vamos construindo um compromisso ético de, dialogicamente, inserir, problematizar e (re)criar essas teorias e metodologias em nossas práticas. O estudo das epistemologias feministas não é novo, mas ainda é pouco valorizado. Sobre o assunto, ver Rago (2012); Rosa e Silva (2017).

x Lugones (2014a) aborda temas como: "colonialidade e poder", "lugar del género en las sociedades precolombinas", "intersexualidad", "igualitarianismo sin género", "igualitarianismo ginecrático", "sistema moderno/colonial de género". Problematiza as violências entre as mulheres negras e a negligência do Estado; Problematiza a exclusão histórica e teórico-pratica das mulheres negras; denuncia a "colonialidade da linguagem". Tem escrito e pesquisado sobre as colonialidades de gênero e poder sob a vida das mulheres negras. Critica o feminismo hegemônico, burguês, branco e eurocêntrico. 
xi Sul é compreendido como metáfora do "sofrimento humano", mais do que uma dimensão exclusivamente geográfica.

xii Ao conceituar o que entende por resistência, María Lugones (2014a) se denomina como uma "teórica da resistência".

xiii Entende-se que Ochoa usa o termo "não formal" para referir-se a experiências educativas e pedagógicas em espaços não-escolarizados.

xiv Sobre "Ciência e Feminismo", ver: Ciencia y feminismo (Harding, 1996).

${ }^{x v}$ Por ciência popular estamos compreendendo a ciência feita a partir da realidade dos/das oprimidos/as e a seu favor; ou ainda, entendemos por ciência popular toda aquela que partir do senso comum, transformada a ciência tem condições de ser novamente apropriada pelos sujeitos de sua origem.

xvi A filósofa Graciela Hierro tem escritos sobre o tem "Ética e Feminismos" (1990).

${ }^{\text {xvii }}$ Usa-se esse termo a partir de Lagarde (2005).

${ }^{\text {xviii }}$ Um dos grandes legados dessa pensadora latinoamericana, é que, nós mulheres, temos que construir alianças, pois os homens, durante toda a história estabeleceram seus pactos, e excluíram/excluem nosotras, estabelecendo os limites de nossa existência.

xix Ver Valcárcel (1997), em "La política de las mujeres". Nessa obra, cuja primeira edição está datada de 1991, Valcárcel escreve sobre "la costumbre del pacto" dos homens. É importante destacar que nessa obra ela aborda temas relacionados aos pactos, que Marcela Lagarde (2006) abordou.

\author{
Informações do artigo / Article Information \\ Recebido em : 28/05/2018 \\ Aprovado em: 19/06/2018 \\ Publicado em: 23/12/2018 \\ Received on May 28th, 2018 \\ Accepted on June 19th, 2018 \\ Published on December 23th, 2018
}

Contribuições no artigo: As autoras foram responsáveis pela elaboração, análise e interpretação dos dados; escrita e revisão do conteúdo do artigo, e aprovação da versão final publicada.

Author Contributions: The authors were responsible for the designing, delineating, analyzing and interpreting the data, production of the manuscript, critical revision of the content and approval of the final version published.

Conflitos de interesse: As autoras declararam não haver nenhum conflito de interesse referente a este artigo.

Conflict of Interest: None reported.

Orcid

Cheron Zanini Moretti

iD http://orcid.org/0000-0002-6297-3129

Graziela Rinaldi da Rosa

http://orcid.org/0000-0002-0347-2949

\section{Como citar este artigo / How to cite this article}

APA

Moretti, C. Z., \& Rosa, G. R. (2018). Descautivar o pensamento pedagógico latino-americano: (Des)colonização e (Des)patriarcalização a partir da crítica feminista. Rev. Bras. Educ. Camp., 3(4), 1105-1127. DOI: http://dx.doi.org/10.20873/uft.2525-4863.2018v3n4p1105

ABNT

MORETTI, C. Z.; ROSA, G. R. Descautivar o pensamento pedagógico latino-americano: (Des)colonização e (Des)patriarcalização a partir da crítica feminista. Rev. Bras. Educ. Camp., Tocantinópolis, v. 3, n. 4, set./dez., p. 1105-1127, 2018. DOI: http://dx.doi.org/10.20873/uft.25254863.2018v3n4p1105 